\title{
Monitoring Leachate Migration in Compacted Soil Using Digital Image Technique
}

\author{
Yamusa Bello Yamusa \\ School of Civil Engineering, Universiti \\ Teknologi Malaysia, Skudai, Malaysia, \\ and Department of Civil Engineering, \\ Nuhu Bamalli Polytechnic, Zaria, Nigeria \\ yamusabello@yahoo.com
}

\author{
Noraliani Alias \\ School of Civil Engineering, \\ Universiti Teknologi Malaysia, \\ Skudai, Malaysia \\ noraliani@utm.my
}

\author{
Radzuan Sa'ari \\ School of Civil Engineering, \\ Universiti Teknologi Malaysia, \\ Skudai, Malaysia \\ radzuans@utm.my
}

\author{
Mushairry Mustaffar \\ School of Civil Engineering, \\ Universiti Teknologi Malaysia, \\ Skudai, Malaysia \\ mushairry@utm.my
}

\author{
Kamarudin Ahmad \\ School of Civil Engineering, \\ Universiti Teknologi Malaysia, \\ Skudai, Malaysia \\ kamarudin@utm.my \\ Loke Kok Foong \\ School of Civil Engineering, \\ Universiti Teknologi Malaysia, \\ Skudai, Malaysia \\ edwinloke84@yahoo.com
}

\begin{abstract}
As leachate has been a source of groundwater contamination worldwide, this paper examines the phenomenon of leachate migration on different gradations of compacted laterite soil used as sanitary landfill liners. Three different soil gradations $(30 \%, 40 \%$ and $50 \%$ with respect to fines content) used in this study were compacted in circular acrylic columns to provide a clear visualization of leachate migration into the soils. Digital image technique was used in capturing photos at successive time intervals to monitor the leachate migration. The captured digital images were fed into Matlab and converted into hue-saturation-intensity (HSI) format. Surfer software then read the HSI and generated $2 \mathrm{D}$ contour plots. The results of the experiments showed that the leachate moves downward faster in the soil gradation with the least fines content. Hydraulic conductivity values decrease with increase in time duration and equally with increase in fines content. The hydraulic conductivities of the leachate for $30 \%, 40 \%$ and $50 \%$ fines were $3.64 \times 10^{-9} \mathrm{~m} / \mathrm{s}, 2.40 \times 10^{-9} \mathrm{~m} / \mathrm{s}$, and $1.24 \times 10^{-9} \mathrm{~m} / \mathrm{s}$ respectively. This reveals that for tropical laterite soils, gradation containing $50 \%$ fines content provides better hydraulic conductivity. The use of noninvasive digital image technique can enable designers/engineers to monitor and visualize the leachate migration in compacted soils in waste containment application systems.
\end{abstract}

Keywords-digital image analysis; monitoring leachate migration; soil gradation; groundwater protection; sanitary landfill

\section{INTRODUCTION}

Groundwater is one of the major sources of water supply for domestic and industrial purposes. However, its purity and quality is compromised because of the way waste is disposed [1]. Groundwater is more reliable and safer to use than surface water as it is less exposed to numerous pollutants [2], though groundwater reliability is subjected to risks due to pollution caused by various sources. One of them is contamination by leachate through landfills because landfills are the final destinations of the majority of waste generated in most urban areas. A liquid that permeated through waste, and contains heavy minerals and suspended materials is defined as landfill leachate [3]. Leachate is generated either from external water or from within the waste mass. Leachate generated from urban solid waste contains heavy metals. These heavy metals leach out from the soil and enter the underlying aquifer, which affects the livelihood of the surrounding community [4-5]. To prevent leachate contamination through landfill, hydraulic barriers known as liners and covers are constructed. Leakage of leachate through hydraulic barriers can be one of the main pollution hazards to groundwater. Therefore, soil materials used as hydraulic barriers must have the following attributes which make them suitable in sanitary landfills:

- They must contain significant amounts of fines and clay minerals [6-8].

- They must have hydraulic conductivity of $\leq 1 \times 10^{-9} \mathrm{~m} / \mathrm{s}$ 11] and unconfined compressive strength of $\geq 200 \mathrm{kN} / \mathrm{m}^{2}$ [12-14].

- Maximum allowable value of volumetric shrinkage should be $4 \%$ [15-18].

The methods generally employed to study and monitor groundwater quality include the use of observation wells and surface/subsurface geophysical techniques [19]. The use of observation wells, suction lysimeters, and phyto-screening are referred as invasive methods, while the use of photography and remote sensing, and rapid noninvasive field survey and screening are referred as noninvasive methods [20]. Some of these noninvasive techniques are briefly explained below.

A deformation measurement technique known as digital image correlation (DIC) is used to compare two digital images 
by calculating their field incremental displacement and locating several small regions in both images to high subpixel accuracy. It is commonly referred to as particle image velocimetry (PIV) in fluid mechanics applications [21]. Light transmission visualization (LTV) is a method which relies on the transitory of electromagnetic energy through the tested media where the distribution of liquid saturation is measured as a variation in light intensity field. [22, 23]. Researches that applied noninvasive imaging techniques produced precise depiction and improved understanding of the multiphase system. Recently, image analysis techniques or digital image techniques (DITs) are used to investigate the migration of fluids within soils [23]. The application of DIT is widely used for double-porosity soil [22-30]. In this research, a noninvasive technique is applied using a DIT that captures the successive migration of leachate through compacted laterite soil in the laboratory to simulate the leachate transportation in actual landfill. Moreover, the effects of soil gradation with respect to fines content are also investigated.

\section{MATERIALS AND METHODS}

The laterite soil used in this study was extracted from Skudai campus of Universiti Teknologi Malaysia located at $1^{\circ} 33^{\prime} 39^{\prime \prime} \mathrm{N}$ and $103^{\circ} 38^{\prime} 44^{\prime \prime} \mathrm{E}$. The soil is classified as MV according to the British Standard Classification [31]. The physical properties as well as the particle size distribution of the laterite soil were determined from laboratory tests and are presented in Table I and Figure 1 respectively. Three different grading sizes (i.e. gravel, sand and fines) were gathered from the sieved natural laterite soil samples and then reconstituted into different gradations. The following gradations were investigated:

- Natural laterite soil with $30 \%$ fines, $40 \%$ sand and $30 \%$ gravel by weight of dry soil denoted as L1.

- Reconstituted laterite soil with $40 \%$ fines, $40 \%$ sand and $20 \%$ gravel by weight of dry soil denoted as L2.

- Reconstituted laterite soil with 50\% fines, $40 \%$ sand and $10 \%$ gravel by weight of dry soil denoted as L3.

The flow chart of the experiment is presented in Figure 2.

TABLE I. LATERITE SOIL PHYSICAL PROPERTIES

\begin{tabular}{|c|c|}
\hline Property & Value \\
\hline Natural Moisture Content, $\%$ & 34 \\
\hline Liquid Limit, \% & 76 \\
\hline Plastic Limit, \% & 42 \\
\hline Plasticity Index, \% & 34 \\
\hline BS Classification & MV \\
\hline Specific Gravity & 2.7 \\
\hline OMC, $\%$ & 30 \\
\hline MDD, Mg/m3 & 1.35 \\
\hline \% Passing BS 63 $\mu \mathrm{m}$ sieve & 30 \\
\hline
\end{tabular}

\section{A. Soil Compaction}

British standard light (BSL) compaction equivalent to standard Proctor compaction is adopted as outlined in BS 1377: 1990: Part 4. In preparing the soil samples, optimum moisture content (OMC) was added to the three different laterite soil gradations. Dried soil sample weighing about $2 \mathrm{~kg}$ of L1 was mixed at $\mathrm{OMC}$ of $30 \%$. To allow proper moisture distribution, the soil was put inside a plastic bag for 24 hours. A circular plastic plate having similar diameter with the acrylic soil column was put on top of the soil before blowing to provide a flat surface. The soil was then compacted in 3 equal layers placed in a circular acrylic column. Each layer was given 27 blows of the $2.5 \mathrm{~kg}$ rammer falling freely from a height of $300 \mathrm{~mm}$. The acrylic soil column has been chosen to monitor and detect the changes occurring inside the whole area of circular column. The same procedure was followed for the L2 and L3 at their optimum moisture contents.

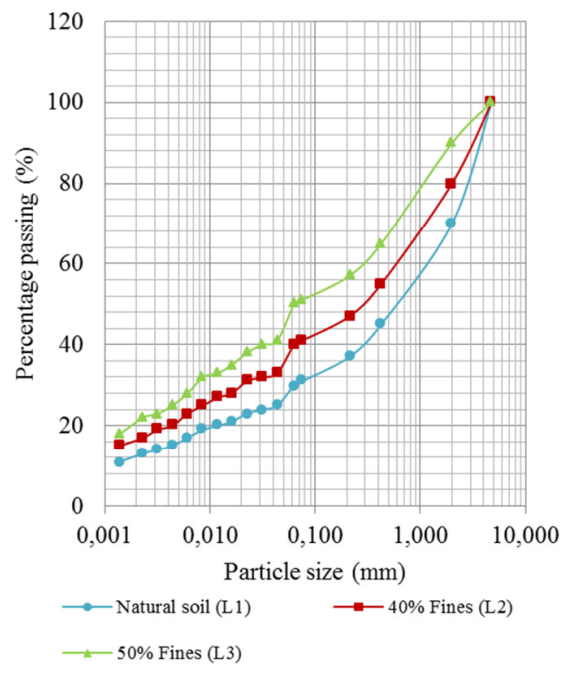

Fig. 1. Particle size distribution curve

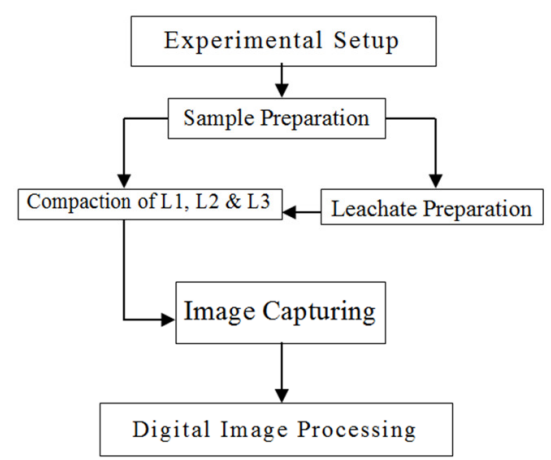

Fig. 2. Flow chart of the experiment

\section{B. Leachate Preparation}

In this experiment, black dye solution is used as the permeant to simulate leachate. It was chosen to enhance the water color, so that it can be visible when migrating down the soil specimen. The chemical composition of the dye comprises of typically sodium chloride and proprietary dyes [32]. About $3.4 \mathrm{~g}$ of dye was mixed with $340 \mathrm{ml}$ of water following the procedure in $[33,34]$. Similarly, authors in [35] prepared their salt solutions $\left(\mathrm{NaCl}, \mathrm{KCl}\right.$, and $\left.\mathrm{CaCl}_{2}\right)$ by dissolving powdered salts in de-ionized water as permeant. These elements were chosen because sodium, potassium and magnesium are usually present at high concentrations in leachates, while chloride has 
high mobility and prevalence in the environment [36]. The leachate was poured instantaneously on the top surface of each compacted sample gently through the side wall of the acrylic columns as shown in Figure 3.

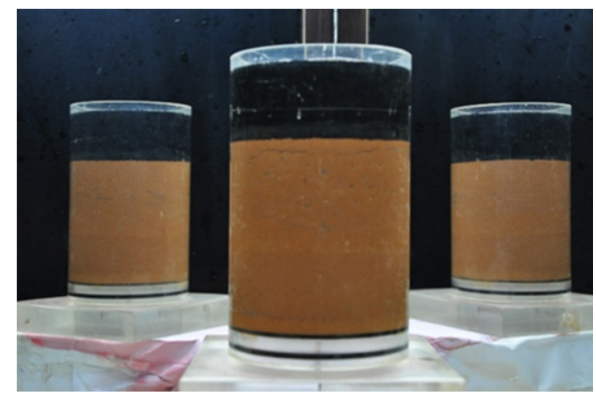

Fig. 3. Leachate on compacted laterite soil sample

\section{Laboratory Experimental Procedure}

Basically, the DIT used in this research adopts the concept explained in [27]. It covers the migration of leachate in a $100 \mathrm{~mm}$ height of soil in acrylic column. The dimension of acrylic cylinder to form the soil column was $150 \mathrm{~mm}$ high, with a diameter of $100 \mathrm{~mm}$ and $6 \mathrm{~mm}$ thickness. The acrylic column was placed in-between a two-faced mirror to provide complete $360^{\circ}$ visualization. These mirrors were placed at $105^{\circ}$ with offset distance of $0.2 \mathrm{~m}$ behind the soil column and facing the digital camera. A Hitachi 40-Watt lamp was installed over the soil column so that the whole setup was illuminated. The acrylic column was chosen to provide a clear visualization of leachate migration into the soil, so the leachate migration through the soil was observed promptly at any point and time throughout the experiment. A Nikon D90 digital camera was used for image acquisition of the leachate migration at designated time intervals. The camera has a sensor size of $15.8 \mathrm{~mm}$ by $23.6 \mathrm{~mm}$ and pixel array of $3216 \times 2136$ pixels (12Mpixels), and operated at minimum shutter speed and aperture. The camera was rigidly positioned with a tripod and a remote control was used to capture images without shaking the camera. The soil column was positioned in a fixed place to avoid any movement. Since the soil columns were in circular shape, images that reflected from the camera and the two mirrors have been combined and corrected to produce a complete single flat area of interest (AOI). A paper with grid lines size of $20 \mathrm{~mm} \times 20 \mathrm{~mm}$ was used to cover the soil column to a height of $100 \mathrm{~mm}$ as shown in Figure 4 . The grid lines were used as a reference mark on a reference image. The reference mark is required in the image registration procedure to transform any distorted image according to the actual scale image. Then a reference image was captured, and the grid line paper was removed from the soil column. Afterwards, leachate was poured on top of the compacted soil sample. Successive images were captured daily to monitor and record the migration behaviour. The digital image technique laboratory experimental setup is presented in Figure 5. Images for all the experiments were taken for one month. The duration of leachate migration from the top surface to the bottom was monitored during this period.

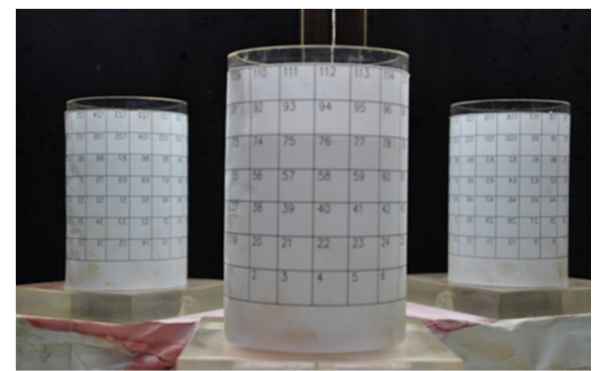

Fig. 4. Soil column with reference grid lines

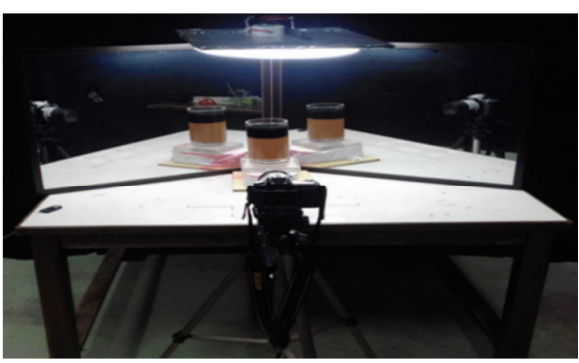

Fig. 5. Laboratory setup

\section{Digital Image Processing}

The digital images captured during the experiments were saved in JPEG format. Images were then processed in Surfer software. This software converts the digital image grid coordinates into surfer grid coordinates. The grid line images were then digitized and saved as generic data files (DAT files) in order to be opened or referenced by a specific application like Matlab, Excel and Surfer. In the object manager of the surfer, a post layer is added and saved as surfer file (SRF file). The DAT files were then copied from the surfer and pasted in Excel. This was necessary in order to sort and filter the values and then saved them as Excel files. The digital image processing routine was carried out using REIVAL (Matlab software). Grid intersections of the image coordinates where extracted using Surfer by digitization. As a parameter requirement in REIVAL routine, these coordinates represent reference or control points. The development of this routine is to achieve image registration procedures such as:

- Conversion of image format from JPEG to HSI.

- Extraction of the HSI value area of interest.

- Saving the intensity value in text files in ASCII format. An affine transformation method was selected to execute the image registration process.

When the image registration was accomplished, a selected AOI was then implemented by the REIVAL routine. The selected AOI was based on the pre-determined AOI. The AOI refers to the part of area of each image that corresponds to the migration area that contains the leachate. The REIVAL routine then converted that AOI into red-green-blue (RGB) and HSI image format. The RGB and HSI intensity values of each pixel from each image were extracted and saved as standard ASCII format. For each image, the REIVAL routine would loop three times to extract and export the intensity values of all three AOIs of the soil column (i.e., the front and the reflected 
sections). Surfer was used to merge the intensity values from the three images and plot the progress of the leachate migration based on the image HSI values. Surfer then read the ASCII data of HSI to generate a 2D contour plot. The schematic diagram is presented in Figure 6.

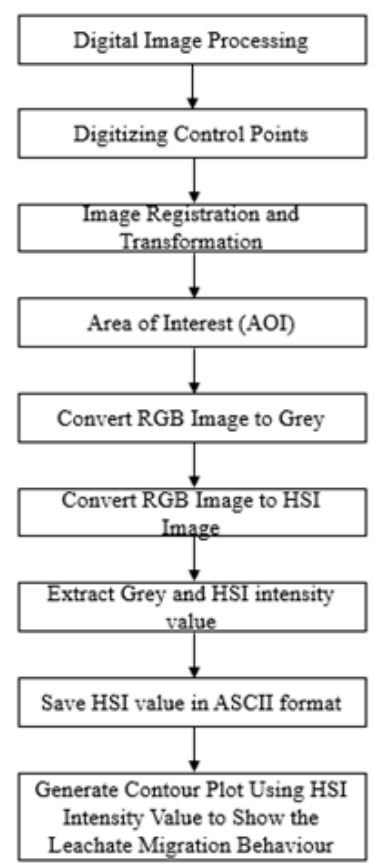

Fig. 6. Schematic of digital image processing [27]

\section{RESULTS AND DISCUSSION}

The effect of laterite soil gradations on leachate migration and the subsequent determination of their hydraulic conductivities using DIT provide an innovative means of visualizing contaminant transportation in compacted soil liners.

\section{A. Effects of Soil Gradation on Leachate Migration}

Contour plots (2D) of HSI intensity value provide details and useful information in order to understand the characteristic of leachate migration behavior. The effects of gradation on the leachate migration for L1, L2 and L3 are presented in Figures 7,8 and 9 respectively. The red color represents the leachate movement inside the soil. Figure 10 shows the measured values of cumulative leachate migration depth as a function of time for L1, L2 and L3 samples from the 2D contour plots. The leachate migration in these experiments shows a rapid progressive penetration within the first day, as the curves of the graph lines are steep within that duration. After the first day, the curve of the graph lines began to incline horizontally at a gradual pace until the seventh day. It remained constant after the seventh day until the end of the experiments depicting a gradual slowing of the downward migration of leachate. This could be explained in terms of tortuosity due to air entrapped at the bottom of the soil column which resists an equal pressure due to the leachate.
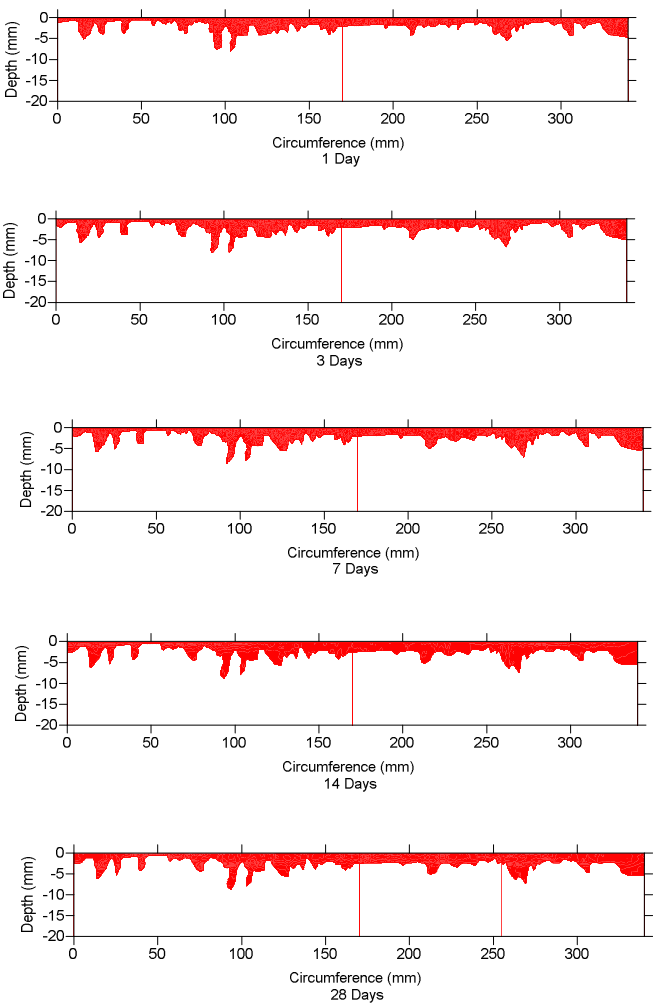

Fig. 7. Leachate migration in soil column for L1
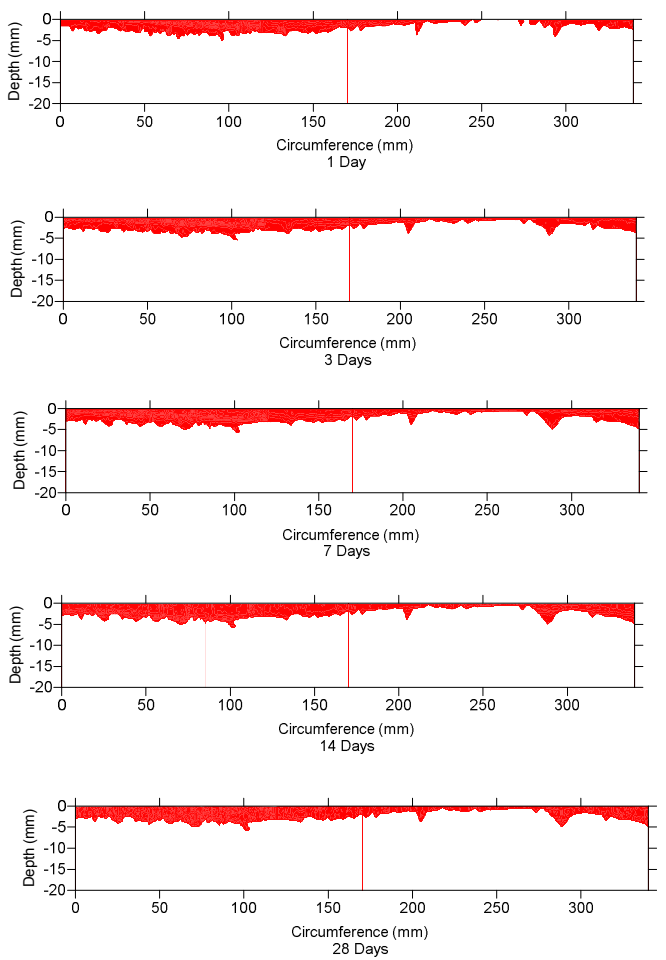

Fig. 8. Leachate migration in soil column for L2 

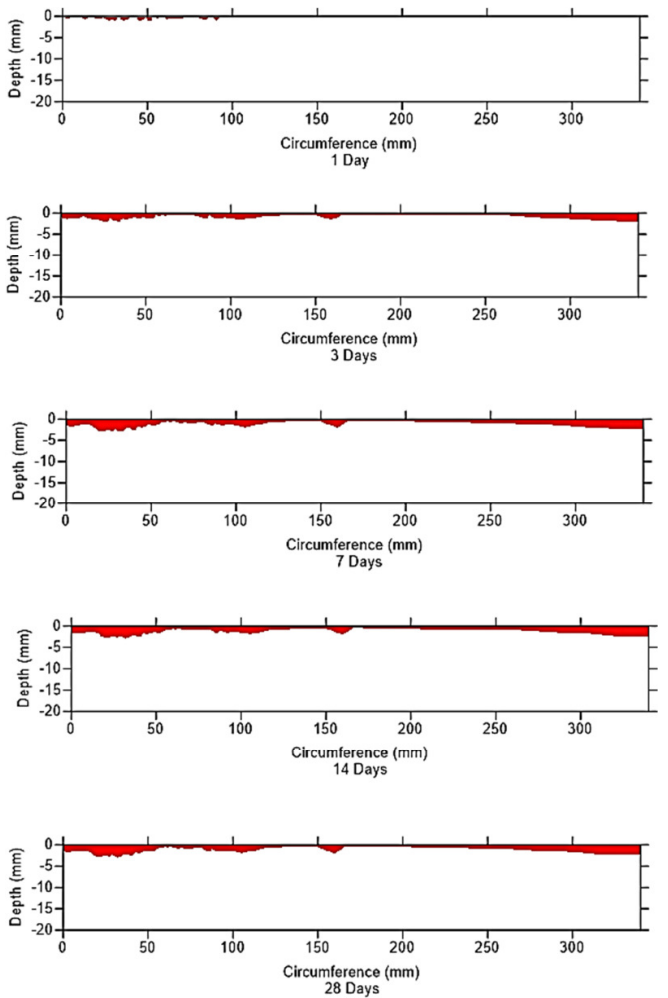

Fig. 9. Leachate migration in soil column for L3

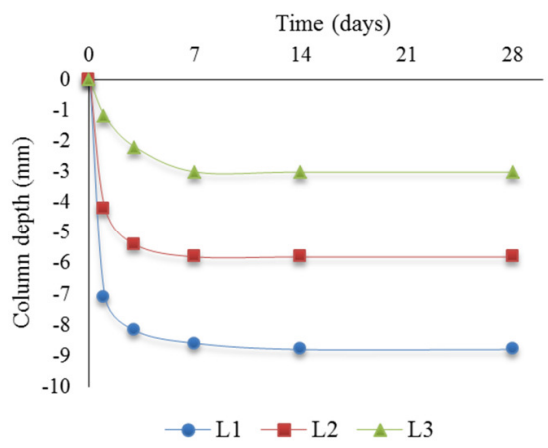

Fig. 10. Measured values of cumulative leachate migration depth as a function of time for L1, L2 and L3 samples

According to [37], tortuosity is used to describe the difference between the actual distance traveled by fluid particles and the macroscopic travel distance, owing to the interconnectivity of pore spaces. A random distribution of interconnected pores in a discrete granular material is considered a porous medium. Any non-interconnected pores, dead-end pores and stagnant pockets are referred to as ineffective pores. L1 demonstrated the fastest migration, covering a depth of $8.8 \mathrm{~mm}$ in a month, followed by L2 and L3 which covered depths of $5.8 \mathrm{~mm}$ and $3.0 \mathrm{~mm}$ respectively. L1 showed the fastest migration because of the less fines content in the soil resulting in a more porous medium. The leachate migrates through the voids easier than in L2 and L3 with higher fines content. Higher fines content means fewer voids inside the soil and less corresponding migration. The effects of fines content on voids of compacted laterite soil for L1, L2, and L3 are illustrated in Figure 11. The compacted soils in acrylic column show clearly that the pores are greater in L1, followed by L2 and then L3 with porosity values at optimum moisture contents of $50 \%, 47.4 \%$ and $47.1 \%$ respectively. Figure 11 shows the voids in the different gradations of compacted laterite soils captured during the digital image technique.

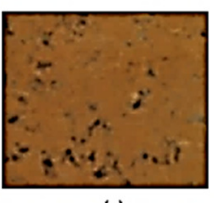

(a)

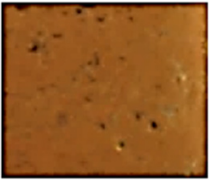

(b)

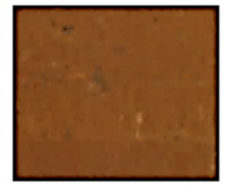

(c)
Fig. 11. Effects of fines content on the voids of compacted laterite soil: (a) L1, (b) L2 and (c) L3

\section{B. Hydraulic Conductivity at Different Gradations}

Generally, hydraulic conductivity decreases with increase in time duration and subsequently with increase in fines content. After one-month monitoring, the hydraulic conductivities of the leachate for L1, L2 and L3 were $3.64 \times 10^{-}$ ${ }^{9} \mathrm{~m} / \mathrm{s}, 2.40 \times 10^{-9} \mathrm{~m} / \mathrm{s}$, and $1.24 \times 10^{-9} \mathrm{~m} / \mathrm{s}$ respectively. Figure 12 illustrates the hydraulic conductivity values against time for different laterite soil gradations.

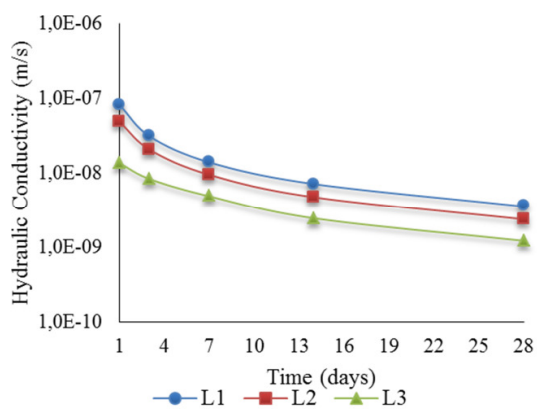

Fig. 12. Hydraulic conductivity values against time for the different laterite soil gradations.

From the experimental observations, it can be seen that the inter-aggregate pores of soil samples for L1 are obviously larger compared to L2 and L3. As hydraulic conductivity varies with the square of the pore radius [38], this condition may cause the leachate to move downward faster when the fines content is decreased. Moreover, capillary pressure influences leachate movement. The pressure induces on the soil particle a compressive stress equal to the weight of the water column [39]. Pores with larger size reduce the capillary pressure that liquid has to overcome to enter those pores and thus move through the soil easier [28]. The samples used in this research for L3 can be considered as liner materials because they have a hydraulic conductivity within the minimum range value of $1 \times 10^{-9} \mathrm{~m} / \mathrm{s}$.

\section{CONCLUSIONS}

Laboratory experimentation was conducted on compacted laterite soil at different gradations to investigate their usability as liners. A digital image processing technique using Matlab 
and Surfer software was applied to monitor the leachate migration behavior in acrylic soil columns. The experiment successfully differentiated the patterns of leachate migration for L1, L2 and L3. The experiment results were determined through the observation of leachate percolation in the test samples, which were compared and the permeability rate was calculated. It was observed that the rate of migration of leachate decreased when the fines content increased. L1 exhibited the fastest migration, followed by L2 and L3. Among these three different gradations, L3 (50\% fines) provided the recommended hydraulic conductivity which can be used as soil liner in waste containment applications. Therefore, the use of noninvasive digital image technique allows designers/engineers to monitor and visualize the migration of leachate in compacted soil.

\section{ACKNOWLEDGEMENT}

Authors want to thankfully acknowledge the financial support given by the Fundamental Research Grant from the Ministry of Higher Education Malaysia (MOHE) vote number R.J130000.7822.4F894 and Universiti Teknlologi Malaysia under GUP Tier 1 vote number Q.J130000.2522.20H53.

\section{REFERENCES}

[1] A. A. Bello, "Hydraulic conductivity of three compacted reddish brown tropical soils", KSCE Journal of Civil Engineering, Vol. 17, No. 5, pp. 939-948, 2013

[2] H. A. Arafat, A. J. Bakel, A. K. Dilger, K. L. Nash, P. G. Rickert, G. F. Vandegrift, "Reclamation of contaminated groundwater using cooking oils in a novel, eco-friendly and high-efficiency solvent extraction process", Desalination, Vol. 321, pp. 9-21, 2013

[3] P. Rushbrook, M. Pugh, Solid Waste Landfills in Middle-and LowerIncome Countries: A Technical Guide to Planning, Design, and Operation, World Bank Tecnhical Paper 426, The World Bank, Washington, DC, USA, 1999

[4] P. Amritha, P. Anilkumar, "Sustainable Solid Waste Management through Landscaped Landfills", Indian Journal of Science and Technology, Vol. 9, No. 29, pp. 1-8, 2016

[5] K. Parameswari, T. Padmini, B. Mudgal, "Assessment of Soil Contamination around Municipal Solid Waste Dumpsite", Indian Journal of Science and Technology, Vol. 8, No. 36, pp. 1-5, 2015

[6] Y. B. Yamusa, N. Z. M. Yunus, K. Ahmad, N. A. Rahman, R. Sa'ari, "Effects of fines content on hydraulic conductivity and morphology of laterite soil as hydraulic barrier", E3S Web of Conferences, International Conference on Civil \& Environmental Engineering, Vol. 34, Article Number 01005, 2018

[7] K. J. Osinubi, A. O. Eberemu, A. O. Bello, A. Adzegah, "Effect of fines content on the engineering properties of reconstituted lateritic soils in waste containment application", Nigerian Journal of Technology, Vol. 31, No. 3, pp. 277-287, 2012

[8] USEPA, Solid Waste Disposal Facility Criteria: Technical Manual. EPA 530-R-93-017, United States Environmental Protection Agency, 1993

[9] H. M. A. Rashid, J. A. D. K. Wanigarathna, L. C. Kurukulasuriya, N. H. Priyankara, A. M. N. Alagiyawanna, T. Saito, K. Kawamoto, "Characterization of locally available soil as a liner material for solid waste landfills in Sri Lanka", Environmental Earth Sciences, Vol. 76, No. 11, pp. 396, 2017

[10] Y. B. Yamusa, K. Ahmad, N. A. Rahman, "Hydraulic Conductivity and Volumetric Shrinkage Properties Review on Gradation Effect of Compacted Laterite Soil Liner", Malaysian Journal of Civil Engineering, Vol. 29, No. 1, pp. 153-164, 2017

[11] D. E. Daniel, Geotechnical Practice for Waste Disposal, Springer Science \& Business Media, 2012
[12] Y. B. Yamusa, K. Ahmad, N. A. Rahman, "Gradation Effect Review on Hydraulic Conductivity and Shear Strength Properties of Compacted Laterite Soil Liner", 11th International Civil Engineering Postgraduate Conference - The 1st International Symposium on Expertise of Engineering Design, Malaysia, September 26-27, 2016

[13] K. J. Osinubi, G. Moses, F. O. P. Oriola, A. S. Liman, "Influence of Molding Water Content on Shear Strength Characteristic of Compacted Cement Kiln Dust Treated Lateritic Soils for Liners and Covers", Nigerian Journal of Technology, Vol. 34, No. 2, pp. 266, 2015

[14] D. E. Daniel, Y. K. Wu, "Compacted clay liners and covers for arid sites", Journal of Geotechnical Engineering, Vol. 119, No. 2, pp. 223237, 1993

[15] A. O. Eberemu, "Desiccation Induced Shrinkage of Compacted Tropical Clay Treated with Rice Husk Ash", International Journal of Engineering Research in Africa, Vol. 6, pp. 45-64, 2011

[16] K. J. Osinubi, A. O. Eberemu, "Desiccation Induced Shrinkage of Compacted Lateritic Soil Treated with Blast Furnace Slag", Geotechnical and Geological Engineering, Vol. 28, No. 5, pp. 537-547, 2010

[17] K. J. Osinubi, C. M. O. Nwaiwu, "Desiccation-induced Shrinkage in Compacted Lateritic Soils", Geotechnical and Geological Engineering, Vol. 26, No. 5, pp. 603-611, 2008

[18] Y. B. Yamusa, A. Kamarudin, A. R. Norhan, R. Sa'ari, N. Z. Yunus, A. Rashid, "Volumetric Shrinkage of Compacted Soil Liner for Sustainable Waste Landfill", Chemical Engineering Transactions, Vol. 63, pp. 613618,2018

[19] T. M. Johnson, K. Cartwright, R. M. Schuller, "Monitoring of Leachate Migration in the Unsaturated Zone in the Vicinity of Sanitary Landfills", Groundwater Monitoring \& Remediation, Vol. 1, No. 3, pp. 55-63, 1981

[20] C. W. Fetter, T. Boving, D. Kreamer, Contaminant Hydrogeology, Waveland Press, 2017

[21] W. A. Take, "Thirty-Sixth Canadian Geotechnical Colloquium: Advances in visualization of geotechnical processes through digital image correlation", Canadian Geotechnical Journal, Vol. 52, No. 9, pp. 1199-1220, 2015

[22] M. Y. Alaziaza, S. K. Ngien, M. M. Bob, S. A. Kamaruddin, W. M. F. Ishak, "Investigation of Light Non-Aqueous Phase Liquid Migration Single and Double-Porosity Soil Using Light Transmission Visualization Method (LTV)", MATEC Web of Conferences, Vol. 47, Article Number 03023, 2016

[23] M. Y. Alazaiza, S. K. Ngien, M. M. Bob, S. A. Kamaruddin, W. M. F. Ishak, "Assessment of the behaviour of soil structure in double-porosity kaolin media using light transmission visualization (LTV) method", International Journal of Geotechnical Engineering, Vol. 11, No. 3, pp. 316-320, 2017

[24] M. Y. Alazaiza, S. K. Ngien, M. M. Bob, S. A. Kamaruddin, W. M. F. Ishak, "Influence of Macro-pores on DNAPL Migration in DoublePorosity Soil Using Light Transmission Visualization Method", Transport in Porous Media, Vol. 117, No. 1, pp.103-123, 2017

[25] M. Y. Alazaiza, S. K. Ngien, M. M. Bob, S. A. Kamaruddin, W. M. F. Ishak, "Application of Light Reflection Method to Observe DNAPL Movement in Different Soil Media", The National Conference for Postgraduate Research, Universiti Malaysia Pahang, Pahang, Malaysia, September 24-25, 2016

[26] L. K. Foong, N. A. Rahman, M. Z. Ramli, "A Laboratory study of vibration effect for deformable double-porosity soil with different moisture content", Malaysian Journal of Civil Engineering, Vol. 28, No. 3, pp. 207-222, 2016

[27] R. Sa'ari, N. H. A. Latiff, N. A. Rahman, Z. M. Yusof, M. Mustaffar, M. A. Hezmi, N. S. Kong, S. A. Kamaruddin, "Application of digital image processing technique in monitoring LNAPL migration in double porosity soil column", Jurnal Teknologi, Vol. 72, No. 3, pp. 23-29, 2015

[28] S. K. Ngien, N. A. Rahman, M. M. Bob, K. Ahmad, R. Sa'ari, R. W. Lewis, "Observation of light non-aqueous phase liquid migration in aggregated soil using image analysis", Transport in Porous Media, Vol. 92, No. 1, pp. 83-100, 2012

[29] S. A. Kamaruddin, W. N. A. Sulaiman, M. P. Zakaria, R. Othman, N. A. Rahman, "Laboratory simulation of LNAPL spills and remediation in 
unsaturated porous media using the image analysis technique: a review", National Postgraduate Conference (NPC), Malaysia, September 19-20, 2011

[30] S. A. Kamarudin, W. N. A. Sulaiman, N. A. Rahman, M. P. Zakaria, M. Mustaffar, R. Sa' ari, "A review of laboratory and numerical simulations of hydrocarbons migrations in subsurface environments", Journal of Environmental Science and Technology, Vol. 4, No. 3, pp. 191-214, 2011

[31] BSI, Methods of Testing Soil for Civil Engineering Purposes (BS 1377:Part 1-9), British Standards Institute, London, 1990

[32] www.ritdye.com

[33] D. B. Stephens, L. M. Coons, "Landfill performance assessment at a semiarid site: Modeling and validation", Groundwater Monitoring \& Remediation, Vol. 14, No. 1, pp. 101-109, 1994

[34] G. Allison, M. Hughes, "The use of environmental chloride and tritium to estimate total recharge to an unconfined aquifer", Soil Research, Vol. 16, No. 2, pp. 181-195, 1978

[35] H. Y. Jo, C. H. Benson, C. D. Shackelford, J. M. Lee, T. B. Edil, "Longterm hydraulic conductivity of a geosynthetic clay liner permeated with inorganic salt solutions", Journal of Geotechnical and Geoenvironmental Engineering, Vol. 131, No. 4, pp. 405-417, 2005

[36] A. A. Bello, K. J. Osinubi, "Attenuative capacity of compacted abandoned dumpsite soils", Electronic Journal of Geotechnical Engineering, Vol. 16, pp. 71-91, 2011

[37] P. Guo, "Dependency of tortuosity and permeability of porous media on directional distribution of pore voids", Transport in Porous Media, Vol. 95, No. 2, pp. 285-303, 2012

[38] J. K. Mitchell, M. Jaber, "Factors controlling the long-term properties of clay liners", in: Waste Containment Systems: Construction, Regulation, and Performance, pp. 84-105, ASCE, 1990

[39] B. Punmia, A. K. Jain, Soil Mechanics and Foundations, Firewall Media, 2005 